\title{
Nanomaterials for Energy Conversion and Storage
}

\author{
Mauro Coelho dos Santos, ${ }^{1}$ Olivera Kesler, ${ }^{2}$ and Arava Leela Mohana Reddy ${ }^{3}$ \\ ${ }^{1}$ Laboratório de Eletroquímica e Materiais Nanoestruturados, Centro de Ciências Naturais e Humanas, Universidade Federal do ABC, \\ Rua Santa Adélia, 166, Bairro Bangu, CEP 09210-170, Santo André SP, Brazil \\ ${ }^{2}$ Department of Mechanical and Industrial Engineering, University of Toronto, 5 King's College Road, Toronto, ON, Canada M5S $3 G 8$ \\ ${ }^{3}$ Department of Mechanical Engineering and Materials Science, Rice University, Houston, TX 77005, USA
}

Correspondence should be addressed to Mauro Coelho dos Santos, mauro.santos@ufabc.edu.br

Received 13 November 2012; Accepted 13 November 2012

Copyright ( 2012 Mauro Coelho dos Santos et al. This is an open access article distributed under the Creative Commons Attribution License, which permits unrestricted use, distribution, and reproduction in any medium, provided the original work is properly cited.

Progress [1] in the area of nanoscience and nanotechnology has pervaded almost all areas of science and technology. Over last couple of decades the ability to manipulate and control materials at an atomic and molecular level (nanometer range) and subsequent understanding of the fundamental processes at nanoscale have led to new avenues. The knowledge thus acquired can be translated into innovative processes, leading to design or fabrication of better products. More importantly, new scientific phenomena and processes have emerged that could provide either revolutionary or novel solutions to the energy, environmental, and sustainable mobility challenges that will face humanity in the 21 st century.

With demand for clean and sustainable energy sources increasing at an exponential rate [1], new material technologies are being explored that could provide cost-effective and environmentally clean solutions to the world's energy problems. Developments in the areas of alternative fuels or energy storage technologies like advanced batteries, fuel cells, ultra capacitors, and biofuels are emerging as strong contenders to petroleum-based sources. Energy derived from clean and renewable sources like solar and wind power have tremendous potential, but the practical use of these sources of energy requires efficient electrical energy storage (EES) technologies that can provide uninterrupted power on demand. In all of these new technologies, nanomaterials are increasingly playing an active role by either increasing the efficiency of the energy storage and conversion processes or by improving device design and performance.

Lithium-ion batteries [2] are one of the great successes of modern materials electrochemistry. Their science and technology have been extensively reported. A lithium-ion battery consists of a lithium-ion intercalation negative electrode (generally graphite) and a lithium-ion intercalation positive electrode (generally the lithium metal oxide, $\mathrm{LiCoO}_{2}$ ), these being separated by a lithium-ion conducting electrolyte, for example, a solution of $\mathrm{LiPF}_{6}$ in ethylene carbonatediethylcarbonate. Although such batteries are commercially successful, we are reaching the limits in performance using the current electrode and electrolyte materials. For new generations of rechargeable lithium batteries, not only for applications in consumer electronics but especially for clean energy storage and use in hybrid electric vehicles, further breakthroughs in materials are essential, such as the use of nanomaterials devices.

Supercapacitors [2] are of key importance in supporting the voltage of a system during increased loads in everything from portable equipment to electric vehicles. There are two general categories of electrochemical supercapacitors: electric double layer capacitors (EDLC) and redox supercapacitors. In contrast to batteries, where the cycle life is limited because of the repeated contraction and expansion of the electrode on cycling, EDLC lifetime is in principle infinite, as it operates solely on electrostatic surface charge accumulation. For redox supercapacitors, some fast faradic charge transfer takes place and results in large pseudocapacitance. Progress in supercapacitor technology can benefit by moving from conventional to nanostructured electrodes. In the case of supercapacitors, the electrode requirements are less demanding than in batteries, at least in terms of electrode compaction, because power prevails over energy density. Thus, the benefits of nanopowders with their highsurface area (primary nanoparticles) are potentially more 
important, hence the staggering interest in nanopowders and their rapid uptake for supercapacitor-based storage sources.

Fuel cell technologies [2] are now approaching commercialization, especially in the fields of portable power sources-distributed and remote generation of electrical energy. Already, nanostructured materials are having an impact on processing methods in the development of lowtemperature fuel cells $\left(T<200^{\circ} \mathrm{C}\right)$, the dispersion of precious metal catalysts, the development and dispersion of nonprecious catalysts, fuel reformation and hydrogen storage, and the fabrication of membrane-electrode assemblies (MEA). Polymer electrolyte membrane fuel cells (PEMFCs) have recently gained momentum for application in transportation and as small portable power sources; whereas phosphoric acid fuel cells (PAFCS), solid oxide fuel cells (SOFCs) and molten carbonates fuel cells (MCFCs) still offer advantages for stationary applications, and especially for cogeneration. Platinum-based catalysts are the most active materials for low-temperature fuel cells fed with hydrogen, reformate, or methanol. To reduce the costs, the platinum loading must be decreased (while maintaining or improving MEA performance), and continuous processes for fabricating MEAs in high volume must be developed. A few routes are being actively investigated to improve the electrocatalytic activity of Pt-based catalysts. They consist mainly of alloying Pt with transition metals or tailoring the Pt particle size.

Due to the potential applications in the field of environmental protection, the photochemistry of $\mathrm{TiO}_{2}$ is a fast growing area both in terms of research and commercial activity [3]. Over the past decade, the level of research activity concerning $\mathrm{TiO}_{2}$ can be appreciated through the exponential increase of relevant research literature produced (11500 publications between 1993 and 2003) and the number of patents regarding, for instance, photocatalysis (3000 between 1996 and 2001, and more recently 2500 in Japan and 500 in USA). These features account for the intense fundamental research activity involving the scientific community. This particular interest is related to the remarkable photoactive properties of $\mathrm{TiO}_{2}$ and therefore to its numerous applications, which are related to two main environmental priorities: environmental protection through heterogeneous catalysis (water purification, air cleaning, and self cleaning materials) and renewable energy production in photoelectrochemical solar cells, dye sensitised solar cells (DSSC). In addition to this the use of $\mathrm{TiO}_{2}$ nanostructures has enhanced the photo electrochemical properties of these materials.

\section{Mauro Coelho dos Santos Olivera Kesler Arava Leela Mohana Reddy}

[2] A. S. Aricò, P. Bruce, B. Scrosati, J. M. Tarascon, and W. Van Schalkwijk, "Nanostructured materials for advanced energy conversion and storage devices," Nature Materials, vol. 4, no. 5, pp. 366-377, 2005.

[3] http://www.cnrs-imn.fr/index.php/en/research-topics-ceses/ nanomaterials-for-solar-energy-conversion-and-storage.

\section{References}

[1] Jagjit Nanda Technical Expert, Materials and Nanotechnology Department Research and Advanced Engineering Ford Motor Company, USA, http://www.autofocusasia.com/production_ manufacturing/nanotechnology_for_automotives.htm. 

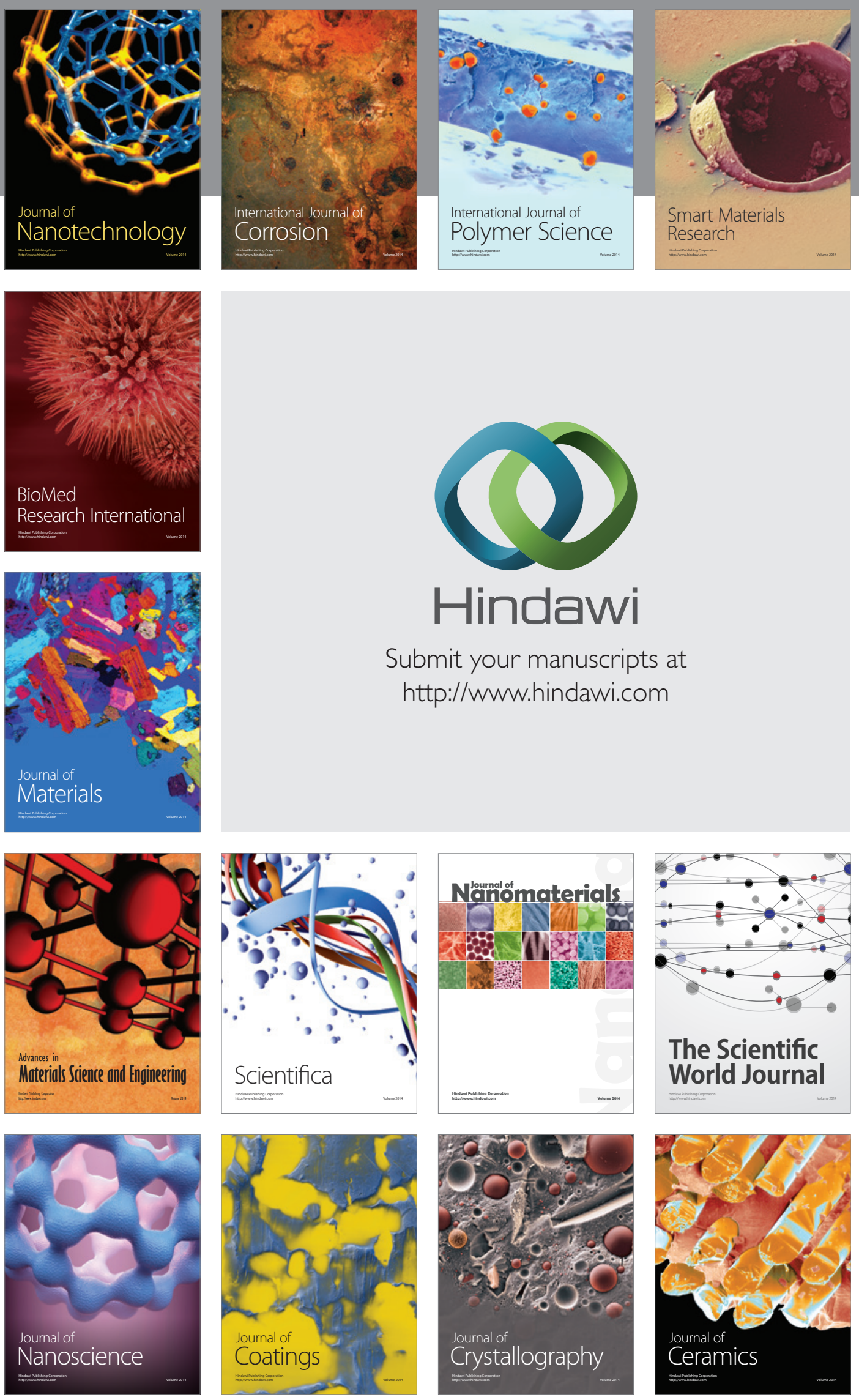

The Scientific World Journal

Submit your manuscripts at

http://www.hindawi.com

\section{World Journal}

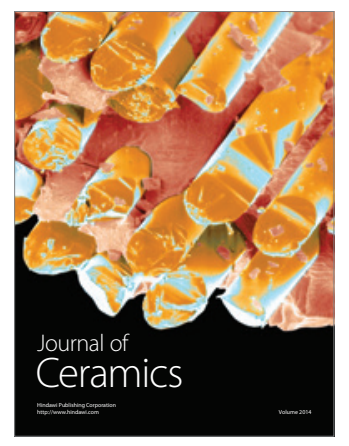

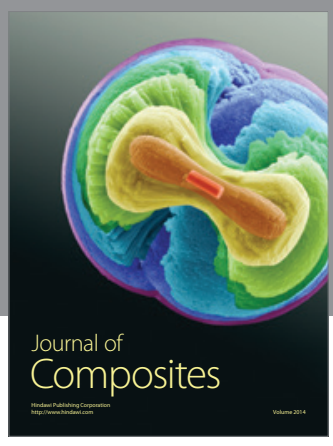
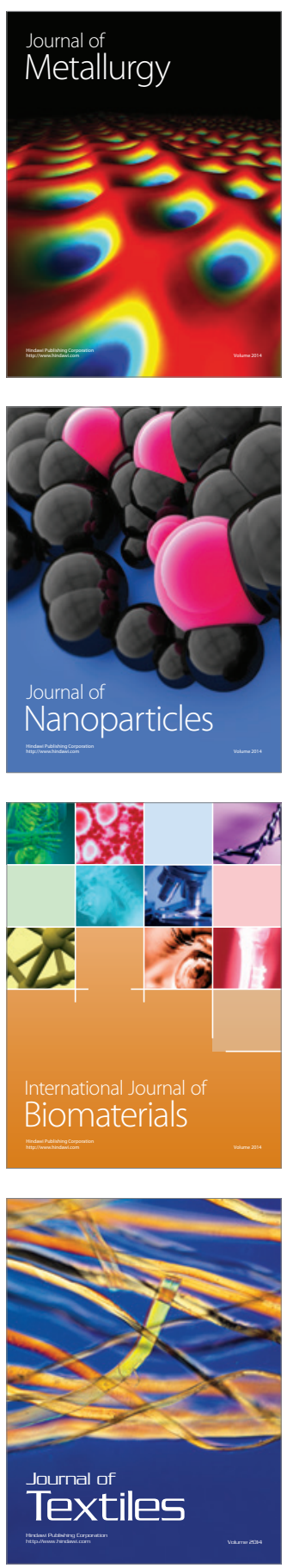